Article

\title{
Effect of Uncertainty in Localized Imperfection on the Ultimate Compressive Strength of Cold-Formed Stainless Steel Hollow Sections
}

\author{
Yanfei Shen *(D) and Rolando Chacón \\ Department of Civil and Environmental Engineering, Universitat Politècnica de Catalunya, \\ 08034 Barcelona, Spain \\ * Correspondence: yanfei.shen@upc.edu; Tel.: +49-688-032-675
}

Received: 13 August 2019; Accepted: 9 September 2019; Published: 12 September 2019

check for updates

\begin{abstract}
Stainless steel has excellent corrosion resistance properties, considerable long-term durability, and good mechanical strength. Hollow sections are a versatile and efficient form for construction applications. The use of cold-formed stainless steel rectangular hollow section (RHS) and square hollow section (SHS) in construction industry grasps the attention of designers conceiving long-term, cost-effective structures. For cold-formed RHS and SHS, localized imperfection $(\omega)$ resulting from rolling and fabrication process is inevitable. $\omega$ has inherent variability and has no definitive characterization. In this paper, statistical analysis of the maximum value of $\omega$ collected from available experimental data is conducted. A new approach utilizing Fourier series to generate the three-dimensional (3D) models of members with random $\omega$ is proposed. Probabilistic studies based on the proposed 3D models are then carried out to evaluate the effect of uncertainty in $\omega$ on the ultimate compressive strength of stainless steel columns with cold-formed RHS and SHS. A total of 21 columns that are prone to local buckling reduction are studied. The results show that uncertainty in $\omega$ has a considerable influence on the columns with relatively higher cross-sectional slenderness.
\end{abstract}

Keywords: stainless steel; cold-formed; uncertainty; localized imperfection

\section{Introduction}

Stainless steel is a steel alloy that contains a minimum of $10.5 \%$ chromium $(\mathrm{Cr})$ content by mass. There is a wide range of stainless steels with varied levels of corrosion resistance and mechanical strength. More than 200 standardized stainless steel grades have hitherto been developed. The basic alloying elements of stainless steel grades are chromium (Cr) and nickel (Ni). According to $\mathrm{Cr}-\mathrm{Ni}$ content by mass, stainless steels can be classified into five basic groups [1,2], as shown in Figure 1 .

The five types are austenitic, ferritic, austenitic-ferritic (duplex), martensitic, and precipitation hardening stainless steels. The first three types have a wide and diverse application in the construction industry, such as building exteriors, facades, and pedestrian bridges. The last two types are for specialist applications [3]. For instance, martensitic grades are commonly used for bearings and turbine blades, and precipitation hardening grades are mostly used in the nuclear and aerospace industry.

Steel hollow sections are a versatile and efficient form for construction applications [4-9]. Buildings that use steel hollow sections have high strength-to-weight ratios. The efficient use of steel hollow sections reduces material usage, resulting in lightweight structures. It allows for large spans, and thus is a choice to achieve the optimal economic benefit. As stainless steels have excellent corrosion resistance properties, considerable long-term durability, and good mechanical strength [10-14], the use of cold-formed stainless steel rectangular hollow section (RHS) and square hollow section (SHS) (shown in Figure 2a) in construction industry has attracted considerable attention. For example, these sections 
have been used in the facade of the building of department of Chemistry, ETH Zürich (Switzerland), shown in Figure 2b, and the support frame of Marqués de Riscal Vineyard (Spain), shown in Figure 2c. Also, they can be used for the main frame structure of residential buildings.

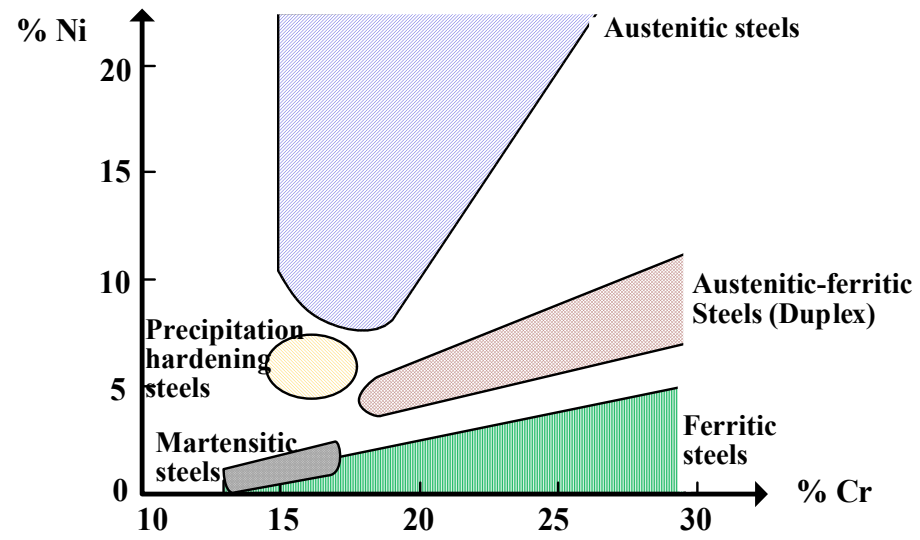

Figure 1. Classification of stainless steels groups based on the content of chromium (Cr) and nickel (Ni).
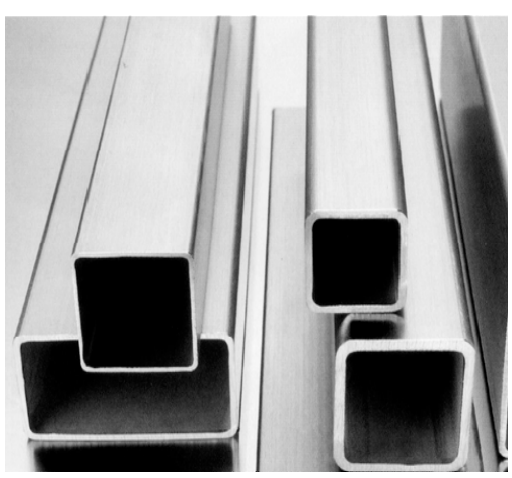

(a)

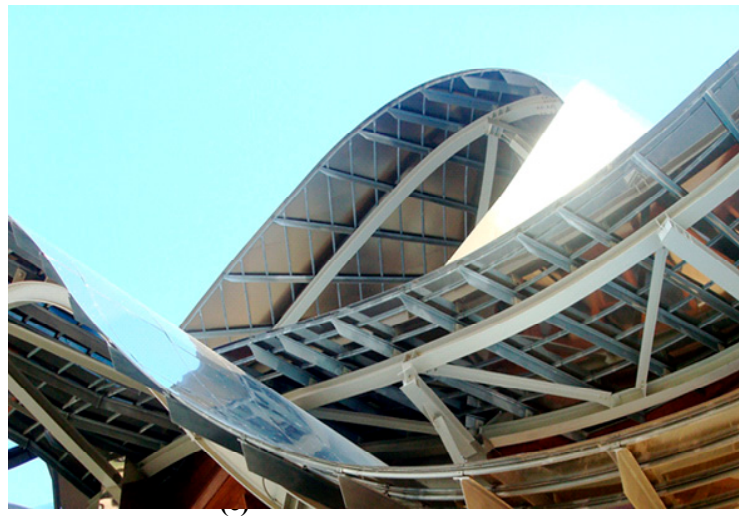

(c)

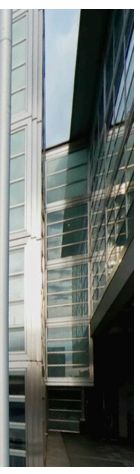

(b)

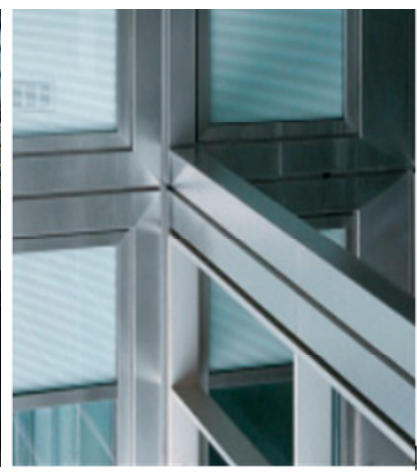

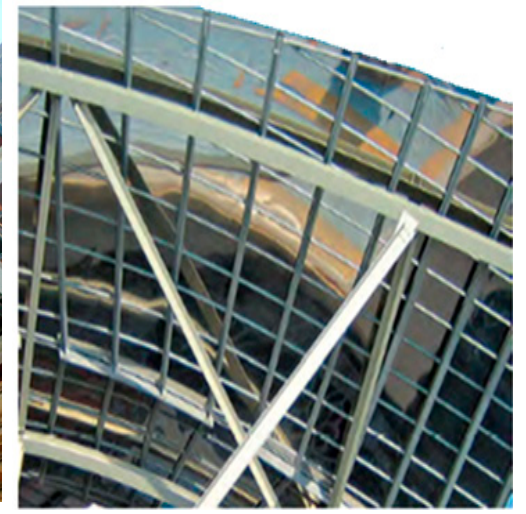

Figure 2. Cold-formed stainless steel rectangular hollow section (RHS) and square hollow section (SHS) and their applications in construction industry. (a) Cold-formed stainless steel RHS and SHS; (b) facade of the building of department of Chemistry, ETH Zürich (Switzerland); (c) support frame of Marqués de Riscal Vineyard (Spain).

Cold-formed hollow sections are manufactured by cold working and welding. There are two different forming methods for cold-formed stainless steel RHS and SHS-direct forming and round to square forming. In direct forming (shown in Figure 3a), the steel strip is transformed into a square or 
rectangular hollow section by bending it through rollers, and welding the seam after that. In round to square forming (shown in Figure 3b), the steel strip is first formed into a circular hollow section and then it is welded. After forming the circular hollow section, square or rectangular shapes are created using profiling rollers.

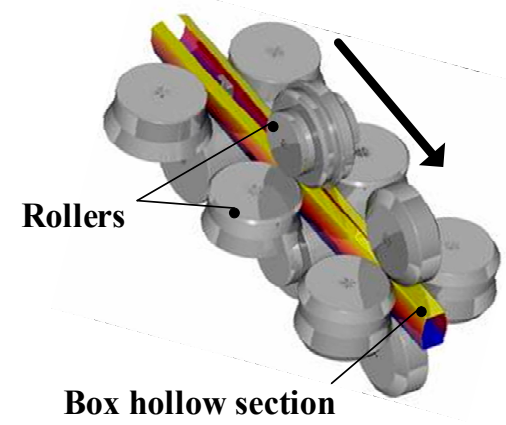

(a)

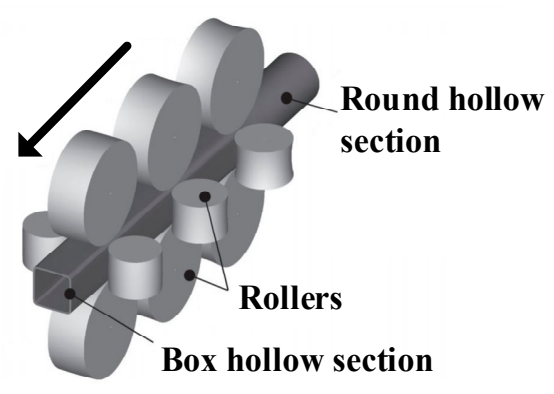

(b)

Figure 3. Two forming methods for cold-formed RHS and SHS. (a) Direct forming [15]; (b) round to square forming [16].

For the two forming methods, localized imperfection $(\omega)$ induced by rolling and fabrication process is inevitable (shown in Figure 4). It has sufficient variability and has no definitive characterization [17]. The study of Wang et al. [18] and Zhao et al. [19,20] showed that both the shape and magnitude of $\omega$ varied randomly in the longitudinal direction for cold-formed members with box section, as shown in Figure 4a. The shape of $\omega$ in the transverse direction (cross-sectional) was convexity/concavity [21,22], which can be modelled by a half-sine wave, as shown in Figure $4 \mathrm{~b}$. In numerical studies, $\omega$ is typically modelled by local buckling mode (shown in Figure 4c) obtained from linear perturbation buckle analysis [23]. The local buckling mode gives idealized $\omega$ and neglects uncertainty in localized imperfection.

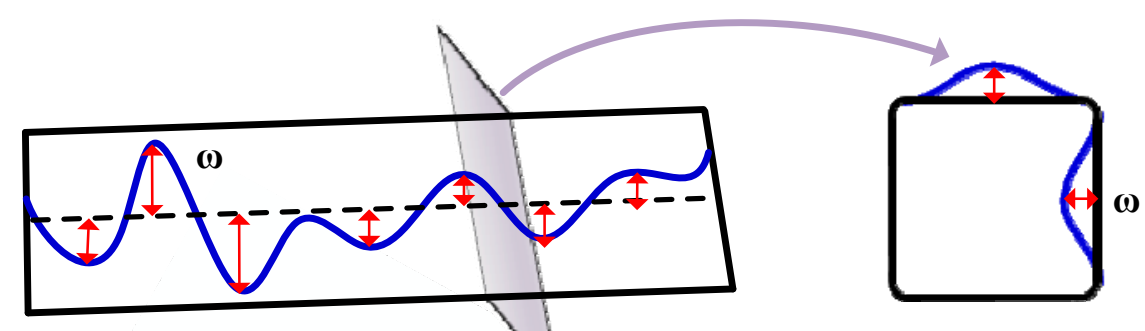

(a)

(b)

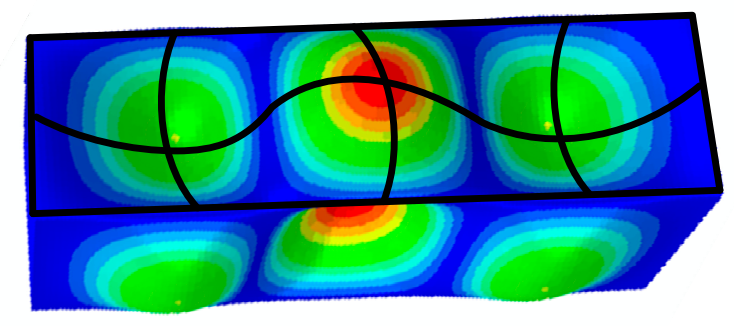

(c)

Figure 4. Localized imperfection $(\omega)$. (a) Random $\omega$ along longitudinal centerline of the surface; (b) $\omega$ in transverse direction (convexity/concavity); (c) idealized $\omega$ obtained from buckle analysis. 
The cross-sectional resistance of cold-formed hollow sections, which contain slender thin-walled elements, is sensitive to initial localized imperfection [24]. These sections undergo local buckling reduction in advance of failure and their ultimate capacity may be influenced by the uncertainty in localized imperfection. Nevertheless, research related to the effect of uncertainty in localized imperfection on the ultimate compressive strength of cold-formed stainless steel RHS and SHS has not been explicitly reported, even though they have been studied for structural applications at the material, member, and system levels [1,17,19-23].

For this purpose, a mathematical approach utilizing Fourier series to generate the 3D models of members with random $\omega$ is proposed in this paper. On the basis of the proposed 3D models, probabilistic studies are carried out to evaluate the effect of uncertainty in $\omega$ on the ultimate compressive strength of the columns.

\section{Statistical Analysis of the Maximum Localized Imperfection ( $\omega$ )}

Although there is a considerable uncertainty when characterizing localized imperfection $(\omega)$ in cold-formed hollow sections, experimental data on the maximum localized imperfection $\left(\omega_{\max }\right)$ are available for the particular case of RHS and SHS stainless steel specimens. A statistical analysis of experimental results of the $\omega_{\max }$ from the literature [19-22,25-31] is carried out in this section. A total of 161 cold-formed stainless steel RHS and SHS samples are collected. A summary of the samples is shown in Table 1. The studied samples refer to the stainless steel grades commonly used in construction. In these references, some studies [21,22] provided the pattern of $\omega$ in the transverse direction (cross-sectional), in which all the reported patterns are very close to a half-sine wave. Few of them reported the variation of localized imperfection in the longitudinal direction. The distribution of $\omega$ in the longitudinal direction for two tubes reported in the work of [19] is shown in Figure 5. It is observed that $\omega$ in the longitudinal direction has a considerable variability and its characterization in a definite closed-form is not feasible.

Table 1. Summary of the samples collected from the literature.

\begin{tabular}{cccc}
\hline Reference & Stainless Steel Groups & Grade & $\begin{array}{c}\text { No. of Samples with } \\
\text { Measured } \boldsymbol{\omega}\end{array}$ \\
\hline B.F. Zheng et al., 2016 [25] & Austenitic & EN1.4301 & 4 \\
I. Arrayago. et al., 2016 [26] & Ferritic & EN1.4003 & 12 \\
B. Young and W.M. Lui, 2005 [21] & Duplex & EN1.4162 & 5 \\
\hline & Austenitic & EN1.4301 & 10 \\
O. Zhao et al., 2015 [20] & Austenitic & EN1.4571 & 6 \\
& Austenitic & EN1.4307 & 6 \\
Austenitic & EN1.4404 & 6 \\
M. Theofanous and L. Gardner, & Duplex & EN1.4162 & 6 \\
2009 [27] & Duplex & EN1.4162 & 8 \\
W.M. Lui et al., 2014 [22] & Duplex & EN1.4462 & 10 \\
S. Afshan and B. Young, 2013 [28] & Duplex & EN1.4162 & 22 \\
2013 [29] & Ferritic & EN1.4003 & 6 \\
M. Bock et al., 2015 [30] & Ferritic & EN1.4509 & 2 \\
I. Arrayago and E. Real, 2015 [31] & Ferritic & EN1.4003 & 8 \\
O. Zhao et al., 2016 [19] & Ferritic & EN1.4003 & 26 \\
& Ferritic & EN1.4003 & 24 \\
\hline
\end{tabular}




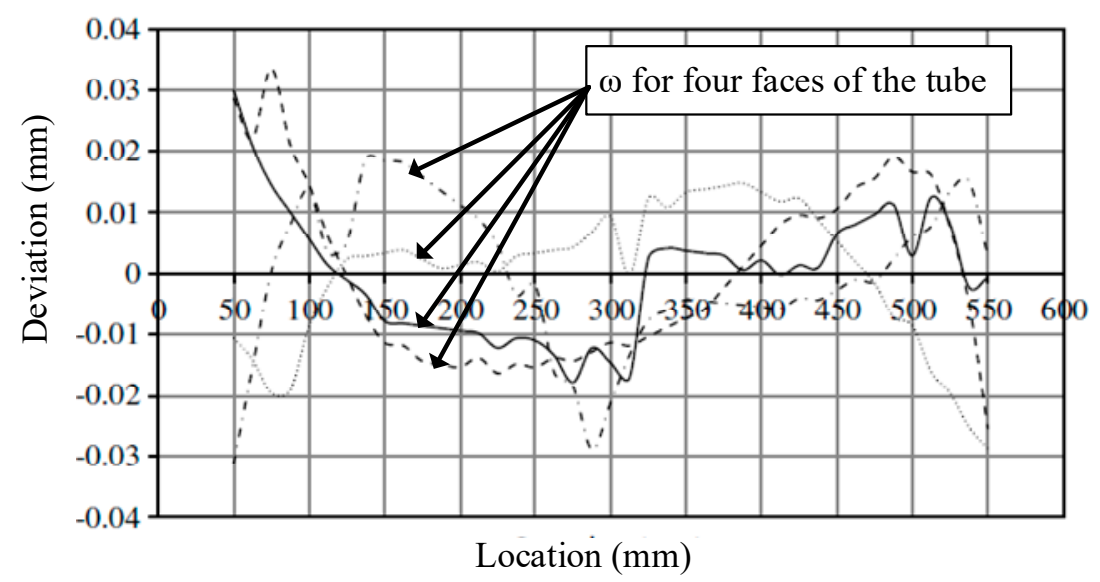

(a)

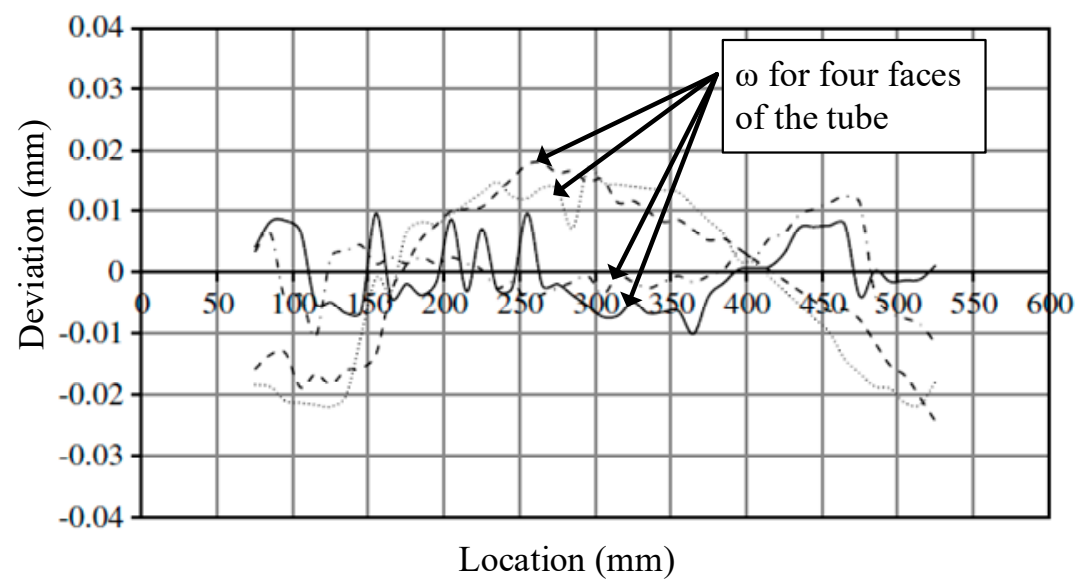

(b)

Figure 5. Distribution of $\omega$ in the longitudinal direction for two tubes reported in the work of [19]. (a) RHS $100 \times 40 \times 2$; (b) SHS $60 \times 60 \times 3$.

The probability distribution for $\omega_{\max }$ among the samples collected in the literature was identified by statistical distribution tests (Anderson-Darling method), as well as from probability plots. Both distribution tests and probability plots were performed using the statistical software Minitab 18 [32].

For the case of distribution tests, Anderson-Darling statistics (AD) and $p$-values measure how well the specified distributions fit the data. For a given sample data and distribution, the smaller the $\mathrm{AD}$, the better the distribution fits the data. Higher $p$-values indicate a better fit, and $p$-values less than 0.05 typically indicate that the data do not follow the specified distribution. The indicator LRT $\mathrm{P}$ is for three-parameter distributions only. A lower LRT P indicates that the related two-parameter distribution can be significantly improved by a third parameter. Goodness of fit test results for 16 different distribution tests are shown in Figure 6a. The Box-Cox transformation and the Johnson transformation are disregarded as the target is to identify probability distribution rather than to perform any transformation. It is found that the log-normal distribution $(\mathrm{AD}=1.016, p$-value $=0.011)$ represents the best fit for the data of $\omega_{\max }$.

Probability plots are another efficient way to determine whether the specified distribution fits the sample data. The closer the data to the middle straight line, the better the distribution fits the data. The probability plot of the sample data is shown in Figure 6b. It is observed that the data points are in close agreement with the center straight line. It again demonstrates that the sample data follow the $\log$-normal distribution. The histogram of $\omega_{\max }$ is shown in Figure 6c. The log-normal distribution is fitted to the histogram. Comparison of the cumulative probability (CDF) curve against the log-normal 
distribution is shown in Figure $6 \mathrm{~d}$, in which CDF determines the probability that an observation will be less than or equal to a certain value.

\begin{tabular}{|lrrr|}
\hline Distribution & $\mathrm{AD}$ & $\mathrm{P}$ & LRT P \\
\hline Normal & 9.172 & $<0.005$ & \\
Box-Cox Transformation & 1.016 & 0.011 & \\
\cline { 1 - 3 } Lognormal & 1.016 & 0.011 & \\
3-Parameter Lognormal & 0.910 & $*$ & 0.540 \\
Exponential & 15.137 & $<0.003$ & \\
2-Parameter Exponential & 9.523 & $<0.010$ & 0.000 \\
Weibull & 4.287 & $<0.010$ & \\
3-Parameter Weibull & 2.994 & $<0.005$ & 0.000 \\
Smallest Extreme Value & 16.361 & $<0.010$ & \\
Largest Extreme Value & 2.873 & $<0.010$ & \\
Gamma & 2.718 & $<0.005$ & \\
3-Parameter Gamma & 2.053 & $*$ & 0.014 \\
Logistic & 7.914 & $<0.005$ & \\
Loglogistic & 1.810 & 0.014 & \\
3-Parameter Loglogistic & 1.628 & $*$ & 0.176 \\
Johnson Transformation & 0.542 & 0.162 & \\
\hline
\end{tabular}

(a)

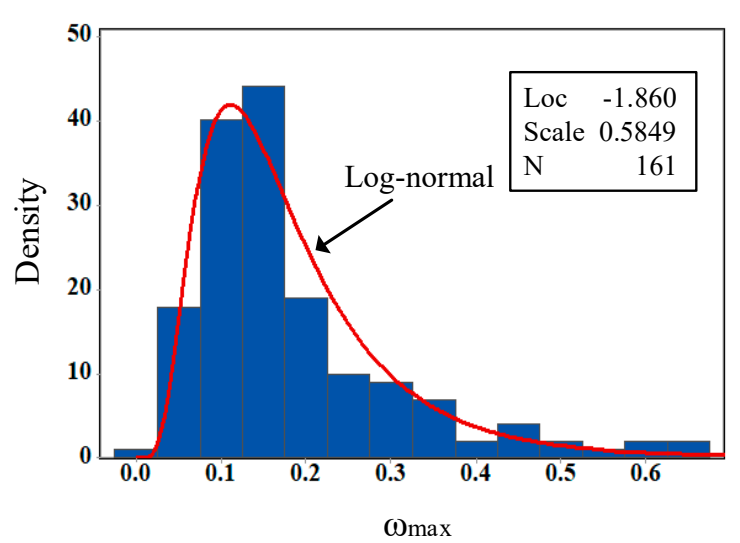

(c)

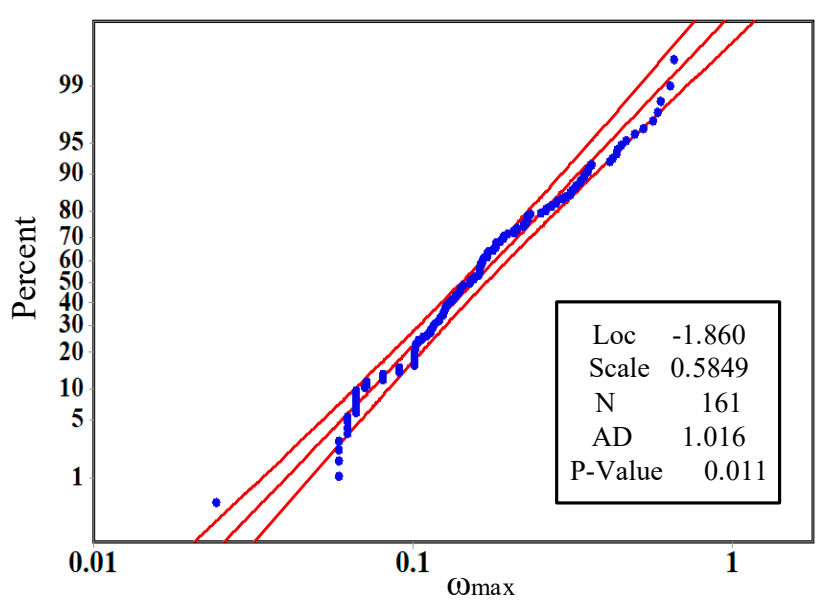

(b)

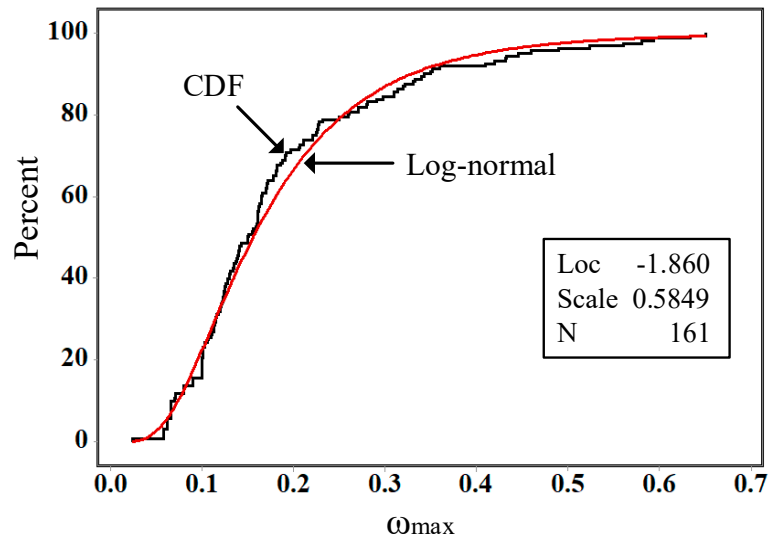

(d)

Figure 6. Identifying probability distribution for $\omega_{\max }$. (a) Goodness of fit test results for 16 different distribution tests; (b) probability plot of $\omega_{\max }$; (c) histogram of $\omega_{\max }$; (d) comparison of cumulative probability $(\mathrm{CDF})$ curve against the log-normal distribution. AD, Anderson-Darling.

Some standards provide the maximum allowable value of localized imperfection in the transverse direction $[33,34]$. The tolerance for convexity/concavity of a cross-section specified in EN-10219-2:2006 [34] is $\min \left\{\omega_{\max } / \mathrm{b}, 0.5 \mathrm{~mm}\right\}$, where $\omega_{\max } / \mathrm{b} \leq 0.008 ; \mathrm{b}$ is the side (straight side of the cross-section) length; and $\omega_{\max }$ represents the maximum deviation from the straight side.

\section{Fourier Series-Based 3D Models with Random $\omega$}

On the basis of a superposition of Fourier series expansion of different functions, a 3D model with random localized imperfection $(\omega)$ is proposed in this section. The Fourier series technique has been widely used for 3D surface modeling [35,36]. For a function $\mathrm{f}(x)$ that is periodic on an interval $[-\mathrm{L}, \mathrm{L}]$, it can be expressed as the Fourier series, given by

$$
\mathrm{f}(x)=\frac{a_{0}}{2}+\sum_{k=1}^{\infty}\left[\mathrm{a}_{k} \cos \left(\frac{k \pi x}{L}\right)+\mathrm{b}_{k} \sin \left(\frac{k \pi x}{L}\right)\right]
$$


where

$$
\begin{gathered}
a_{0}=\frac{1}{L} \int_{-L}^{L} f(x) d x \\
a_{k}=\frac{1}{L} \int_{-L}^{L} f(x) \cos \left(\frac{k \pi x}{L}\right) d x(k=0,1,2,3, \cdots), \\
b_{k}=\frac{1}{L} \int_{-L}^{L} f(x) \sin \left(\frac{k \pi x}{L}\right) d x(k=1,2,3, \cdots) .
\end{gathered}
$$

Assume a surface consists of $n \times m$ points in a 3D coordinate system, where $X$ coordinate represents the longitudinal (length) direction, $\mathrm{Y}$ represents the transverse (width) direction, and $\mathrm{Z}$ represents deviation from the flat surface parallel to the XY plane. For a point $\left(x_{i}, y_{j}, z_{i j}\right)(\mathrm{I}=1,2, \ldots, m ; j=1,2$, $\ldots, n)$ on the surface, $z_{i j}$ governs localized imperfection $(\omega)$. All $z_{i j}$ elements comprise an $n \times m$ matrix $[Z]$, which can be determined by

$$
\begin{gathered}
{[\mathbf{Z}]=\left[\mathbf{F}_{1}\right]+\left(\left[\mathbf{F}_{2}\right]-\left[\mathbf{F}_{1}\right]\right)[\mathbf{S}]} \\
{\left[\mathbf{F}_{1}\right]=\left[\begin{array}{cccccc}
\mathrm{f}_{1}\left(\mathrm{x}_{1}\right) & \mathrm{f}_{1}\left(\mathrm{x}_{2}\right) & \cdots & \mathrm{f}_{1}\left(\mathrm{x}_{i}\right) & \cdots & \mathrm{f}_{1}\left(\mathrm{x}_{m}\right) \\
\mathrm{f}_{1}\left(\mathrm{x}_{1}\right) & \mathrm{f}_{1}\left(\mathrm{x}_{2}\right) & \cdots & \mathrm{f}_{1}\left(\mathrm{x}_{i}\right) & \cdots & \mathrm{f}_{1}\left(\mathrm{x}_{m}\right) \\
\vdots & \vdots & \vdots & \vdots & \vdots & \vdots \\
\mathrm{f}_{1}\left(\mathrm{x}_{1}\right) & \mathrm{f}_{1}\left(\mathrm{x}_{2}\right) & \cdots & \mathrm{f}_{1}\left(\mathrm{x}_{i}\right) & \cdots & \mathrm{f}_{1}\left(\mathrm{x}_{m}\right)
\end{array}\right]_{n \times m}} \\
{\left[\mathbf{F}_{2}\right]=\left[\begin{array}{cccccc}
\mathrm{f}_{2}\left(\mathrm{x}_{1}\right) & \mathrm{f}_{2}\left(\mathrm{x}_{2}\right) & \cdots & \mathrm{f}_{2}\left(\mathrm{x}_{i}\right) & \cdots & \mathrm{f}_{2}\left(\mathrm{x}_{m}\right) \\
\mathrm{f}_{2}\left(\mathrm{x}_{1}\right) & \mathrm{f}_{2}\left(\mathrm{x}_{2}\right) & \cdots & \mathrm{f}_{2}\left(\mathrm{x}_{i}\right) & \cdots & \mathrm{f}_{2}\left(\mathrm{x}_{m}\right) \\
\vdots & \vdots & \vdots & \vdots & \vdots & \vdots \\
\mathrm{f}_{2}\left(\mathrm{x}_{1}\right) & \mathrm{f}_{2}\left(\mathrm{x}_{2}\right) & \cdots & \mathrm{f}_{2}\left(\mathrm{x}_{i}\right) & \cdots & \mathrm{f}_{2}\left(\mathrm{x}_{m}\right)
\end{array}\right]_{n \times m},}
\end{gathered}
$$

where $\mathrm{f}_{1}\left(\mathrm{x}_{\mathrm{i}}\right)$ and $\mathrm{f}_{2}\left(\mathrm{x}_{\mathrm{i}}\right)$ are functions that are decomposed into Fourier series.

$[\mathrm{S}]$ is an $\mathrm{m} \times \mathrm{m}$ diagonal matrix,

$$
[\mathbf{S}]=\left[\begin{array}{cccc}
\sin \left(\pi \mathrm{y}_{j} / \mathrm{B}\right) & 0 & \cdots & 0 \\
0 & \sin \left(\pi \mathrm{y}_{j} / \mathrm{B}\right) & \cdots & 0 \\
\vdots & \vdots & \ddots & \vdots \\
0 & 0 & \cdots & \sin \left(\pi \mathrm{y}_{j} / \mathrm{B}\right)
\end{array}\right]_{m \times m}
$$

$$
\begin{aligned}
& \left(\left[\mathbf{F}_{2}\right]-\left[\mathbf{F}_{1}\right]\right)[\mathbf{S}]= \\
& {\left[\begin{array}{ccccc}
{\left[\mathrm{f}_{2}\left(\mathrm{x}_{1}\right)-\mathrm{f}_{1}\left(\mathrm{x}_{1}\right)\right] \sin \left(\frac{\pi \mathrm{y}_{1}}{\mathrm{~B}}\right)} & \cdots & {\left[\mathrm{f}_{2}\left(\mathrm{x}_{i}\right)-\mathrm{f}_{1}\left(\mathrm{x}_{i}\right)\right] \sin \left(\frac{\pi \mathrm{y}_{1}}{\mathrm{~B}}\right)} & \cdots & {\left[\mathrm{f}_{2}\left(\mathrm{x}_{m}\right)-\mathrm{f}_{1}\left(\mathrm{x}_{m}\right)\right] \sin \left(\frac{\pi \mathrm{y}_{1}}{\mathrm{~B}}\right)} \\
{\left[\mathrm{f}_{2}\left(\mathrm{x}_{1}\right)-\mathrm{f}_{1}\left(\mathrm{x}_{1}\right)\right] \sin \left(\frac{\pi \mathrm{y}_{2}}{\mathrm{~B}}\right)} & \cdots & {\left[\mathrm{f}_{2}\left(\mathrm{x}_{i}\right)-\mathrm{f}_{1}\left(\mathrm{x}_{i}\right)\right] \sin \left(\frac{\pi \mathrm{r}_{2}}{\mathrm{~B}}\right)} & \cdots & {\left[\mathrm{f}_{2}\left(\mathrm{x}_{m}\right)-\mathrm{f}_{1}\left(\mathrm{x}_{m}\right)\right] \sin \left(\frac{\pi \mathrm{y}_{2}}{\mathrm{~B}}\right)} \\
\vdots & \vdots & \vdots & \vdots & \vdots \\
{\left[\mathrm{f}_{2}\left(\mathrm{x}_{1}\right)-\mathrm{f}_{1}\left(\mathrm{x}_{1}\right)\right] \sin \left(\frac{\pi \mathrm{y}_{n}}{\mathrm{~B}}\right)} & \cdots & {\left[\mathrm{f}_{2}\left(\mathrm{x}_{i}\right)-\mathrm{f}_{1}\left(\mathrm{x}_{i}\right)\right] \sin \left(\frac{\pi \mathrm{y}_{n}}{\mathrm{~B}}\right)} & \cdots & {\left[\mathrm{f}_{2}\left(\mathrm{x}_{m}\right)-\mathrm{f}_{1}\left(\mathrm{x}_{m}\right)\right] \sin \left(\frac{\pi \mathrm{y}_{n}}{\mathrm{~B}}\right)}
\end{array}\right] .}
\end{aligned}
$$

The fundamental principles of generating 3D surfaces with random $\omega$ are illustrated by the following. $\mathrm{f}_{1}\left(\mathrm{x}_{\mathrm{i}}\right)$ and $\mathrm{f}_{2}\left(\mathrm{x}_{\mathrm{i}}\right)$ are two functions that are decomposed into Fourier series with random coefficients. $\left[\mathbf{F}_{1}\right]$ and $\left[\mathbf{F}_{2}\right]$ govern two curved surfaces, as shown in Figure $7 \mathrm{a}$, where $\mathrm{L}$ and $\mathrm{B}$ are the length and width of the surface, respectively. Localized imperfection $(\omega)$ is determined by matrix $\left(\left[\mathbf{F}_{2}\right]\right.$ $-\left[\mathbf{F}_{1}\right]$ ) [S]. It consists of two components: the transverse variation and longitudinal variation, as shown in Figure $7 \mathrm{~b}$. The shape and magnitude of $\omega$ in the longitudinal direction depends on the curve along the longitudinal centerline. It is determined by the function $\left[f_{2}\left(x_{i}\right)-f_{1}\left(x_{i}\right)\right] \sin (\pi / 2)$. The shape of $\omega$ in the transverse direction is modelled by a half-sine-wave, as its shape in the transverse direction reported in most literatures is convexity/concavity. The half-sine-wave is determined by the function $\left[\mathrm{f}_{2}\left(\mathrm{x}_{\mathrm{i}}\right)-\mathrm{f}_{1}\left(\mathrm{x}_{\mathrm{i}}\right)\right] \sin \left(\pi \mathrm{y}_{\mathrm{j}} / \mathrm{B}\right)$, as shown in Figure $7 \mathrm{~b}$, where the two half-sine waves correspond to $\left(x_{a}, y_{j}\right)$ 
and $\left(x_{b}, y_{j}\right)(j=0,1, \ldots, m)$. The generated surface with random $\omega$ is determined by $\left[\mathbf{F}_{1}\right]+\left(\left[\mathbf{F}_{2}\right]-\left[\mathbf{F}_{1}\right]\right)$ $[\mathrm{S}]$, as shown in Figure 7c.

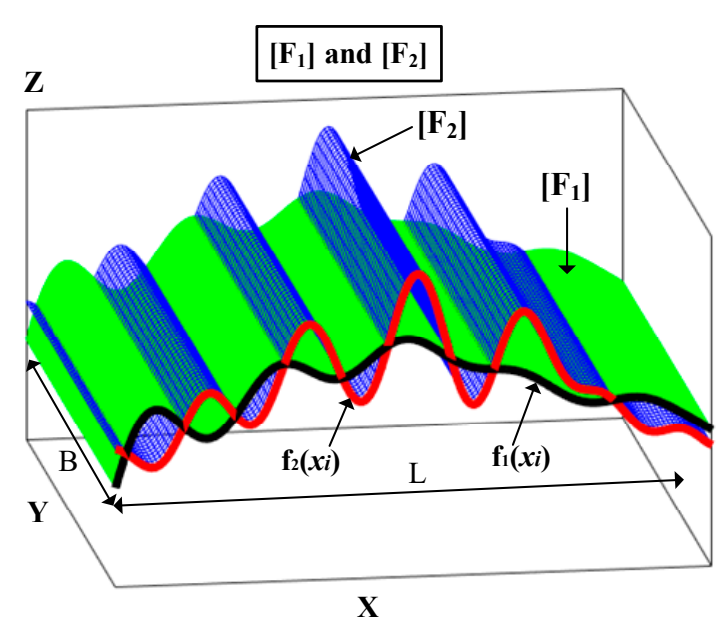

(a)

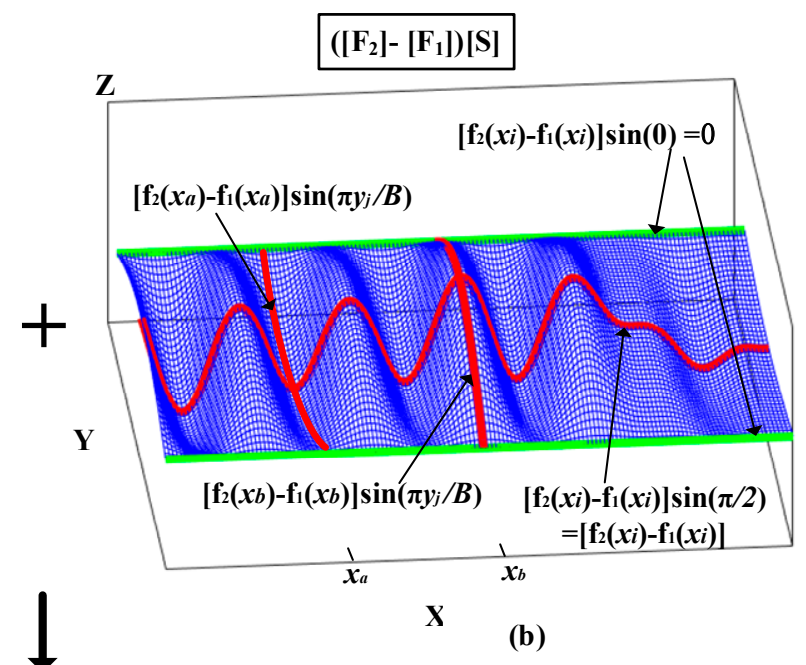

$\left[\mathrm{F}_{1}\right]+\left(\left[\mathrm{F}_{2}\right]-\left[\mathrm{F}_{1}\right]\right)[\mathrm{S}]$

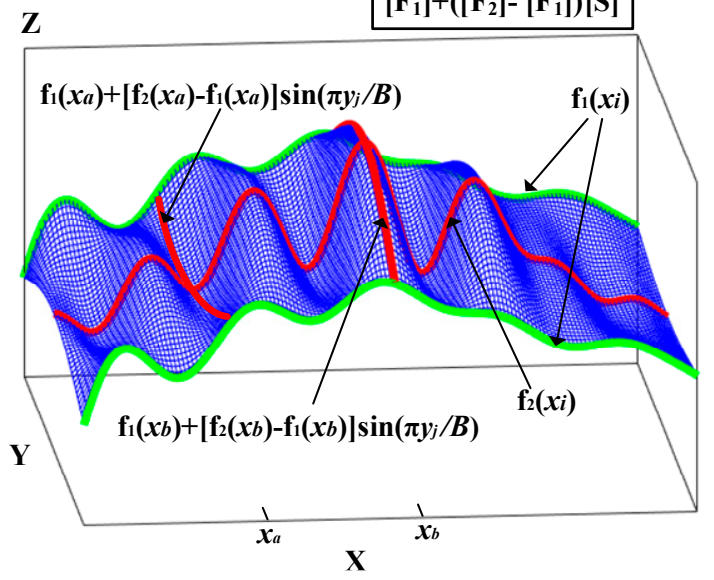

(c)

Figure 7. Development of 3D surface with random $\omega$. (a) Two surfaces determined by $\left[\mathrm{F}_{1}\right]$ and $\left[\mathrm{F}_{2}\right]$; (b) surface determined by $\left(\left[\mathrm{F}_{2}\right]-\left[\mathrm{F}_{1}\right]\right)[\mathrm{S}]$; (c) surface determined by $\left[\mathrm{F}_{1}\right]+\left(\left[\mathrm{F}_{2}\right]-\left[\mathrm{F}_{1}\right]\right)[\mathrm{S}]$.

The 3D model of a member with random $\omega$ is finally assembled by four surfaces. It should be mentioned that in order to fit the four faces together, relevant coordinate transformation should be conducted. Coordinate transformation depends on assembling order and the position of the surface in a 3D space. For developing a 3D model of RHS and SHS with round corners, additional curved surfaces representing round corners need to be modelled. The generated 3D model for a typical surface with random $\omega$ and half-sine edges is shown in Figure 8a, and for a typical member with random $\omega$ and half-sine edges, it is shown in Figure $8 b$. 


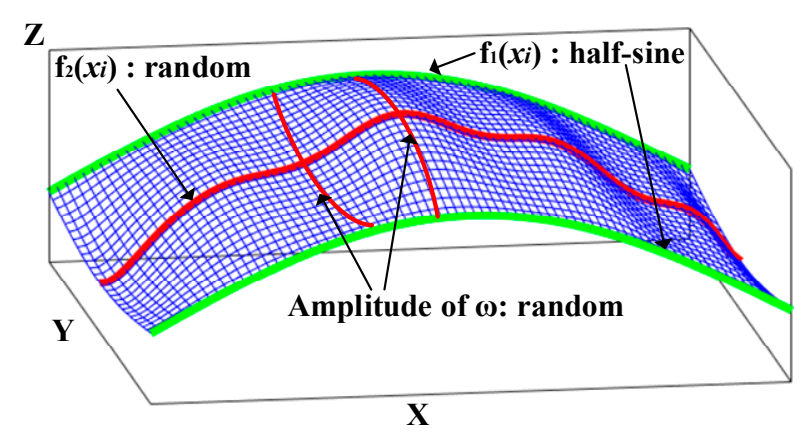

(a)

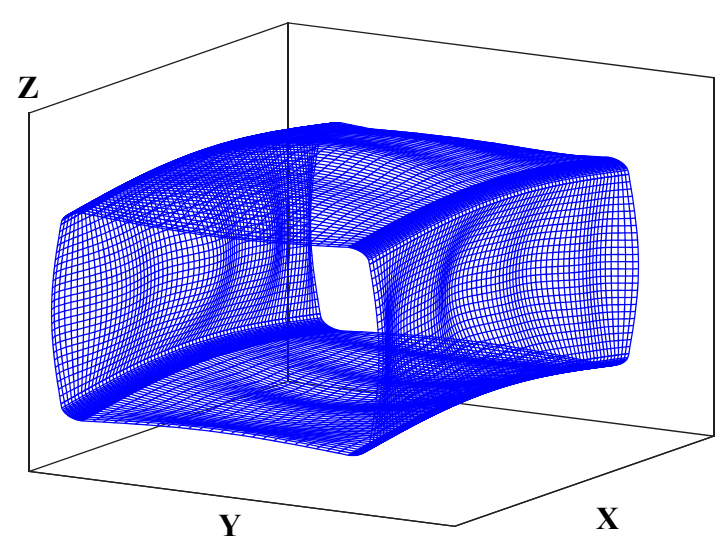

(b)

Figure 8. Generated 3D model. (a) Surface with random $\omega$ and half-sine edges; (b) member with random $\omega$ and half-sine edges.

\section{Case Study of Stainless Steel Columns with Cold-Formed RHS and SHS}

A total of 21 stainless steel columns with cold-formed RHS and SHS are selected among the tested specimens reported in the literature [21,28,29,37-39]. The studied columns have cross-sectional slenderness $\left(\lambda_{1}\right)$ higher than 0.776 . This is to ensure that the columns undergo cross-sectional local buckling reduction before they reach the ultimate compressive strength. According to the work of [24], the nominal compressive strength of a column with RHS or SHS is determined by $\min \left\{\mathrm{P}_{\text {ne }}, \mathrm{P}_{\mathrm{nl}}\right\}$, where $P_{n e}$ and $P_{n l}$ are the nominal global buckling strength and local buckling strength, respectively. The interaction between global and local buckling depends on $\lambda_{1}$ and is determined by

$$
\begin{gathered}
\text { When } \lambda_{l} \leq 0.776 \mathrm{P}_{\mathrm{nl}}=\mathrm{P}_{\mathrm{ne}}, \\
\text { When } \lambda_{l}>0.776 \frac{\mathrm{P}_{\mathrm{nl}}}{\mathrm{P}_{\mathrm{ne}}}=\lambda_{\mathrm{l}}^{-0.8}-0.15 \lambda_{\mathrm{l}}^{-1.6} \text {. }
\end{gathered}
$$

A plot of $P_{n l} / P_{\text {ne }}$ versus $\lambda_{1}$ is shown in Figure 9. It should be pointed out that, although Equations (10) and (11) are developed based on carbon steel members, the two equations are applicable to stainless steel members with cold-formed RHS and SHS and give an accurate prediction [40,41].

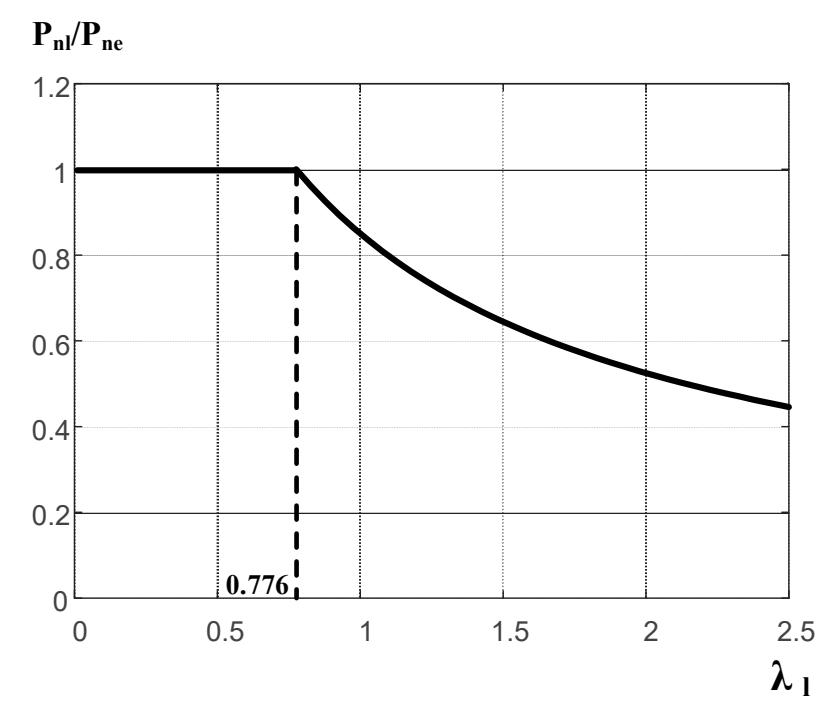

Figure 9. The interaction between global and local buckling strength. 
Details of the studied columns are shown in Table 2. Namely, $b_{1}, b_{2}$, and $t$ are the depth, width, and thickness of the hollow cross-section, respectively; $\mathrm{R}$ is external radius of the round corner; $\mathrm{L}$ is the length of the column; $\lambda_{c}$ and $\lambda_{1}$ are member slenderness and cross-sectional slenderness, respectively; $\omega_{\mathrm{g}}$ is the amplitude of global member imperfection (out-of-straightness). $\omega_{\mathrm{g}}$ is not reported for some cases of stub columns $\left(\lambda_{c} \leq 0.2\right)$, while the shape of $\omega_{\mathrm{g}}$ is adopted as a half-sine wave for other columns.

Table 2. Details of the selected stainless steel columns for probabilistic studies.

\begin{tabular}{|c|c|c|c|c|c|c|c|c|c|}
\hline Reference & Specimen & $\begin{array}{c}b_{1} \\
(\mathrm{~mm})\end{array}$ & $\begin{array}{c}b_{2} \\
(\mathrm{~mm})\end{array}$ & $t(\mathrm{~mm})$ & $\mathrm{R}(\mathrm{mm})$ & $\mathrm{L}(\mathrm{mm})$ & $\lambda_{c}$ & $\lambda_{1}$ & $\omega_{\mathrm{g}}$ \\
\hline \multirow{2}{*}{ [37] } & SHS2L300 & 50.1 & 50.3 & 1.58 & 2.8 & 300 & 0.14 & 0.8 & - \\
\hline & RHS1L3000 & 140.1 & 79.9 & 3.01 & 10.0 & 3000 & 0.71 & 0.9 & 0.927 \\
\hline \multirow{7}{*}{ [28] } & C5L200 & 100.1 & 50.1 & 2.5 & 3.7 & 200 & 0.18 & 1.0 & - \\
\hline & C6L200 & 150.0 & 50.1 & 2.5 & 4.3 & 200 & 0.18 & 1.5 & - \\
\hline & C6L550 & 150.1 & 50.2 & 2.49 & 4.5 & 550 & 0.48 & 1.4 & 0.5 \\
\hline & C5L900R & 100.1 & 50.4 & 2.49 & 3.5 & 900 & 0.79 & 0.8 & 0.857 \\
\hline & C6L900 & 150.4 & 50.3 & 2.47 & 4.7 & 900 & 0.79 & 1.3 & 0.857 \\
\hline & C6L1200 & 149.9 & 50.5 & 2.46 & 4.5 & 1200 & 1.04 & 1.2 & 1.143 \\
\hline & C6L1550 & 150.5 & 50.3 & 2.49 & 4.5 & 1550 & 1.35 & 1.0 & 1.476 \\
\hline \multirow{3}{*}{ [29] } & $\begin{array}{c}\text { RHS } 120 \times 80 \times \\
3-S C 2\end{array}$ & 120.0 & 80.0 & 2.83 & 6.7 & 362 & 0.16 & 0.82 & - \\
\hline & $\begin{array}{c}\text { RHS } 120 \times 80 \times \\
3-1077\end{array}$ & 120.0 & 79.9 & 2.87 & 6.8 & 1077 & 0.35 & 0.8 & 0.95 \\
\hline & $\begin{array}{c}\text { RHS } 120 \times 80 \times \\
3-1577\end{array}$ & 120.0 & 79.9 & 2.81 & 6.4 & 1577 & 0.51 & 0.8 & 0.96 \\
\hline \multirow{3}{*}{ [38] } & R1L1200 & 120.1 & 40.1 & 1.94 & 5.0 & 1199 & 0.48 & 1.1 & 0.254 \\
\hline & R1L2000 & 120.2 & 40.0 & 1.95 & 5.1 & 2000 & 0.80 & 1.0 & 0.444 \\
\hline & R3L2000 & 120.0 & 80.0 & 2.80 & 6.7 & 2000 & 0.44 & 0.8 & 0.381 \\
\hline \multirow{4}{*}{ [39] } & $\begin{array}{c}\text { SHS100 } \times 100 \times \\
2-\text { LC- } 2 \mathrm{~m}\end{array}$ & 99.8 & 99.9 & 1.86 & 3.2 & 2000 & 0.73 & 1.0 & 0.1 \\
\hline & $\begin{array}{c}\text { RHS100 } \times 50 \times \\
2-L C J-2 \mathrm{~m}\end{array}$ & 99.8 & 49.8 & 1.83 & 3.7 & 2000 & 0.80 & 0.9 & 0.6 \\
\hline & $\begin{array}{c}\text { RHS100 } \times 50 \times \\
2-\mathrm{LC}-1 \mathrm{~m}\end{array}$ & 99.8 & 50.0 & 1.82 & 3.6 & 1000 & 0.69 & 1.0 & 0.1 \\
\hline & $\begin{array}{c}\text { RHS } 120 \times 80 \times \\
3-\mathrm{LC}-1 \mathrm{~m}\end{array}$ & 120.0 & 80.2 & 2.86 & 5.7 & 1001 & 0.45 & 0.8 & 1 \\
\hline \multirow{2}{*}{ [21] } & $160 \times 80 \times 3$ & 160.1 & 80.8 & 2.87 & 9.0 & 600 & 0.09 & 1.2 & - \\
\hline & $200 \times 110 \times 4$ & 196.2 & 108.5 & 4.01 & 13.0 & 600 & 0.07 & 1.1 & - \\
\hline
\end{tabular}

\section{Generation of 3D Models of the Studied Columns and Finite Element (FE) Analysis}

The structural behavior of stainless steel columns with random $\omega$ was studied using finite element (FE) software Abaqus 6.13 [42]. The Fourier series-based 3D model of the columns with random $\omega$ was generated by Matlab 2017b [43]. Then, the generated models were imported into Abaqus to conduct the FE analysis. The input file of ABAQUS is generated by MATLAB script.

\subsection{Generation of 3D Model with Random $\omega$ Using MATLAB}

The development of the coefficient of Fourier series terms of function $f_{2}(x)$ and $f_{2}(x)$ was performed in Matlab. For the stub columns $\left(\lambda_{c} \leq 0.2\right)$, Fourier series expansion of function $f_{1}(x)$ generated a straight line. For other columns, $\mathrm{f}_{1}(\mathrm{x})$ generated half-sine-waves, where the magnitude of the half-sine wave was taken as the corresponding $\omega_{\mathrm{g}}$, shown in the above Table 2. For all columns, coefficients of Fourier series terms of function $\mathrm{f}_{2}(\mathrm{x})$ were defined as random. The maximum amplitude of the modelled $\omega$ for each column was limited to $\min \{0.008 \mathrm{~b}, 0.5\}$. For each column, 50 models with random values of localized imperfection $\omega$ were produced. The developed Matlab program automatically created a Python script associated with an Input file operated in Abaqus. It is worth pointing out that the distribution of the generated random $\omega_{\max }$ followed a log-normal distribution as the experimental data of $\omega_{\max }$. This was explicitly set in the developed Matlab program. 


\subsection{FE Analysis Using ABAQUS}

Abaqus/Standard (implicit solver) was employed for FE analysis. A four-node shell element with reduced integration (S4R) was used. It allows transverse shear deformation, and accounts for finite membrane strains and arbitrarily large rotations. The number of integration points through the thickness is five (Simpson's rule). The load-displacement response was predicted using an incremental procedure based on arc-length methods. The modified Riks method [44], which is available in Abaqus, was used. On the basis of a mesh convergence study, at least ten elements across the plate widths were used. Stainless steels have considerable non-linear stress-strain response. To accurately predict the structural behavior of the studied columns, the adopted material property for each column was obtained from a corresponding uniaxial tensile stress-strain coupon test. Details of the parameters that describe the stress-strain curves can be found in the literature [21,28,29,37-39]. For all the models, edge elements at both ends (top and bottom) were kinematically coupled and connected to two control points where the relevant degrees of freedom were constrained.

Spread of plasticity through cross-section and along member length was traced by distributed plasticity approach. In the FE analysis, residual stresses have to be considered as they may have negative effects on the ultimate capacity of a structure. As the effect of through-thickness longitudinal bending residual stresses on the global behavior of stainless steel members with box sections is dominant [45], only longitudinal bending residual stresses were considered, and they were implicitly included in the stress-strain curves obtained from the tensile coupons test. For each model of the column with random $\omega_{\max }$, geometrically and materially nonlinear analysis with imperfections (GMNIA) was carried out to determine the ultimate compressive strength of the column.

\section{Effect of Uncertainty in $\omega$ on the Ultimate Compressive Strength of the Studied Columns}

A probabilistic study was carried out to investigate the effect on the uncertainty in localized imperfection $(\omega)$ on the distribution of the ultimate strength of the stainless steel columns with cold-formed RHS and SHS. The experimental results and predicted results of the columns with random localized imperfection are shown in Table 3. Namely, $\mathrm{P}_{\mathrm{u} \text {-EXP }}$ is the ultimate compressive strength obtained from experiment; $\mathrm{P}_{\mathrm{u} \text {-rand }}$ is the predicted ultimate compressive strength for each model (each column have 50 models); $\mu$ and COV are the mean value and coefficients of variation, respectively; and $\left|\varepsilon_{\max }\right|$ is the maximum value of relative error for each set of 50 models.

Table 3. Experimental results and predicted results for the studied columns. COV, coefficients of variation.

\begin{tabular}{|c|c|c|c|c|c|c|}
\hline Specimen & $\lambda_{1}$ & $\begin{array}{c}P_{\mathbf{u}-E X P} \\
(\mathbf{k N})\end{array}$ & $\begin{array}{c}\mu\left(\mathbf{P}_{\mathrm{u}-\text { rand }}\right) \\
(\mathrm{kN})\end{array}$ & $\begin{array}{c}\mu\left(\mathbf{P}_{\mathrm{u}-\mathrm{rand}}\right) \\
/ \mathbf{P}_{\mathbf{u}-\mathrm{EXP}}\end{array}$ & $\operatorname{COV}\left(P_{u-\text { rand }}\right)$ & $\left|\varepsilon_{\max }\right|$ \\
\hline SHS2L300 & 0.84 & 175.7 & 177.8 & 0.985 & 0.086 & 0.043 \\
\hline RHS1L3000 & 0.88 & 513.5 & 454.7 & 0.980 & 0.073 & 0.077 \\
\hline C5L200 & 0.95 & 370.1 & 387.5 & 1.103 & 0.036 & 0.065 \\
\hline C6L200 & 1.47 & 404.1 & 413.2 & 0.931 & 0.175 & 0.171 \\
\hline C6L550 & 1.41 & 353.2 & 388.1 & 1.026 & 0.212 & 0.175 \\
\hline C5L900R & 0.84 & 336.0 & 326.0 & 1.007 & 0.055 & 0.029 \\
\hline C6L900 & 1.32 & 333.5 & 345.2 & 0.988 & 0.139 & 0.098 \\
\hline C6L1200 & 1.20 & 284.5 & 300.7 & 1.142 & 0.108 & 0.185 \\
\hline C6L1550 & 1.02 & 230.0 & 249.2 & 1.008 & 0.095 & 0.102 \\
\hline RHS $120 \times 80 \times 3-S C 2$ & 0.82 & 441.0 & 434.2 & 1.072 & 0.093 & 0.086 \\
\hline RHS $120 \times 80 \times 3-1077$ & 0.79 & 463.0 & 432.1 & 1.018 & 0.109 & 0.075 \\
\hline RHS $120 \times 80 \times 3-1577$ & 0.79 & 382.0 & 401.5 & 0.973 & 0.045 & 0.058 \\
\hline
\end{tabular}


Table 3. Cont.

\begin{tabular}{|c|c|c|c|c|c|c|}
\hline Specimen & $\lambda_{1}$ & $\begin{array}{c}P_{\mathbf{u}-\text { EXP }} \\
(\mathbf{k N})\end{array}$ & $\begin{array}{c}\mu\left(\mathbf{P}_{\mathrm{u}-\text {-rand }}\right) \\
(\mathbf{k N})\end{array}$ & $\begin{array}{c}\mu\left(\mathbf{P}_{\mathbf{u}-\text { rand }}\right) \\
/ \mathbf{P}_{\mathbf{u}-\mathrm{EXP}}\end{array}$ & $\operatorname{COV}\left(P_{u-\text { rand }}\right)$ & $\left|\varepsilon_{\max }\right|$ \\
\hline R1L1200 & 1.07 & 167.0 & 153.5 & 1.02 & 0.129 & 0.115 \\
\hline R1L2000 & 0.97 & 141.3 & 137.9 & 0.999 & 0.088 & 0.055 \\
\hline R3L2000 & 0.79 & 394.0 & 355.7 & 1.071 & 0.071 & 0.047 \\
\hline SHS100 $\times 100 \times 2-L C-2 m$ & 1.04 & 176.0 & 183.0 & 1.066 & 0.162 & 0.096 \\
\hline RHS100 × $50 \times 2-$ LCJ- $2 \mathrm{~m}$ & 0.92 & 157.0 & 145.3 & 1.041 & 0.085 & 0.117 \\
\hline RHS100 $\times 50 \times 2-L C-1 \mathrm{~m}$ & 0.96 & 163.0 & 151.4 & 1.090 & 0.133 & 0.102 \\
\hline RHS120 × $80 \times 3-L C-1 \mathrm{~m}$ & 0.79 & 448.0 & 415.5 & 1.053 & 0.079 & 0.086 \\
\hline $160 \times 80 \times 3$ & 1.24 & 537.3 & 505.0 & 0.939 & 0.158 & 0.139 \\
\hline $200 \times 110 \times 4$ & 1.07 & 957.0 & 928.0 & 0.958 & 0.081 & 0.070 \\
\hline
\end{tabular}

For all the studied columns, $\mu\left(\mathrm{P}_{\mathrm{u} \text {-rand }}\right) / \mathrm{P}_{\mathrm{u} \text {-EXP }}$ and COV $\left(\mathrm{P}_{\mathrm{u} \text {-rand }}\right)$ versus $\lambda_{1}$ are plotted in Figure $10 \mathrm{a}, \mathrm{b}$, respectively. A plot of $\left|\varepsilon_{\max }\right|$ against $\lambda_{1}$ is shown in Figure 10c. It is observed that the value of $\mu\left(\mathrm{P}_{\mathrm{u} \text {-rand }}\right) / \mathrm{P}_{\mathrm{u} \text {-EXP }}$ ranges between 0.931 and 1.103 for all the columns, except the column with $\lambda_{1}=1.20$. Compared with $P_{\mathrm{u}-\mathrm{EXP}}$, the value of $\mu\left(\mathrm{P}_{\mathrm{u} \text {-rand }}\right)$ for most columns with relatively lower cross-sectional slenderness $\left(\lambda_{1}<1.0\right)$ is overestimated, while the value of $\mu\left(\mathrm{P}_{\mathrm{u} \text {-rand }}\right)$ for columns with higher cross-sectional slenderness seems to be underestimated. For the column with $\lambda_{1}=1.20$, the value of $\mu\left(\mathrm{P}_{\mathrm{u} \text {-rand }}\right) / \mathrm{P}_{\mathrm{u} \text {-EXP }}$ is 1.142. It indicates that most predicted results (from the 50 models with random $\omega)$ significantly overestimate the experimental result. This may be because the value of the actual maximum localized imperfection for this column, which is not reported in the work of [28], is relatively larger compared with the modelled $\omega$, whose maximum value is $\min \{0.008 b, 0.5\}$.

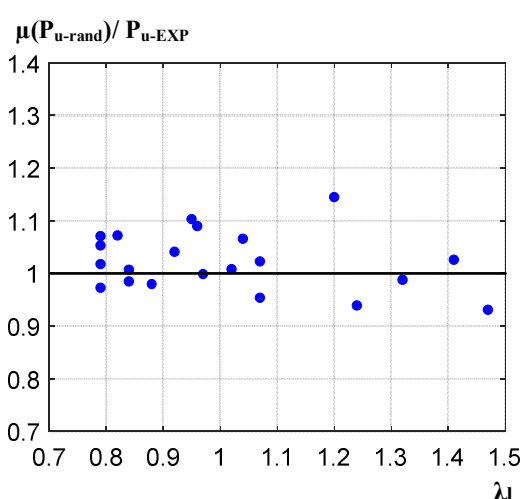

(a)

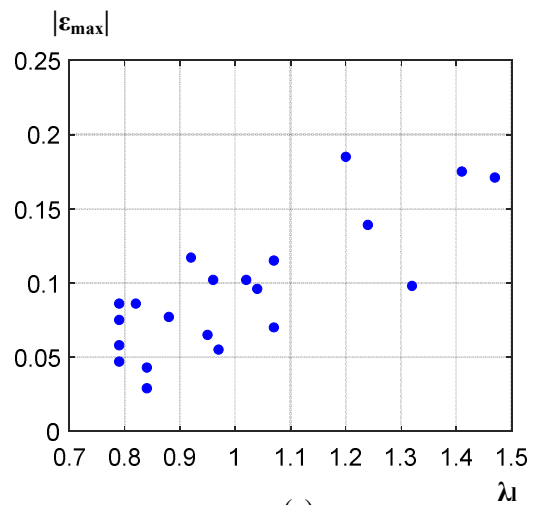

(c)

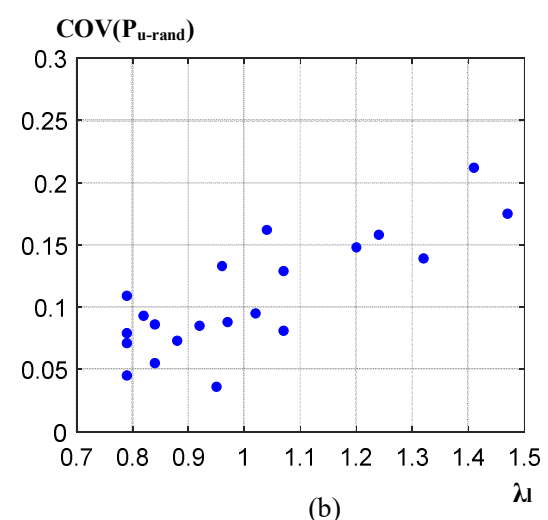

(b) 
On the other hand, both $\operatorname{COV}\left(\mathrm{P}_{\mathrm{u} \text {-rand }}\right)$ and $\left|\varepsilon_{\max }\right|$ increase as $\lambda_{1}$ increases. One explanation is that, the larger the cross-sectional slenderness, the more sensitive the column is to initial localized imperfection. Consequently, the change in the value of modelled localized imperfection can result in a larger discrepancy in the ultimate compressive strength.

For the columns with relatively lower cross-sectional slenderness $\left(\lambda_{1}<1.0\right)$, the values of COV $\left(\mathrm{P}_{\mathrm{u} \text {-rand }}\right)$ and $\left|\varepsilon_{\max }\right|$ are less than 0.13 and 0.12 , respectively. The result indicates that uncertainty in $\omega$ has no considerable influence on the ultimate compressive strength of these columns. This may be because the columns with relatively lower cross-sectional slenderness are still not sensitive to initial localized imperfection. Besides, the result indicates that $\omega$ can statistically be modelled as deterministic for these columns, such as using measured $\omega$ in the experimental study.

For the columns with $\lambda_{1} \geq 1.2, \operatorname{COV}\left(\mathrm{P}_{\mathrm{u}-\text { rand }}\right)$ are around 0.139-0.238 and the maximum value of $\left|\varepsilon_{\max }\right|$ is $17.5 \%$. It demonstrates that random $\omega$ results in largely scattered ultimate compressive strength for the columns with larger cross-sectional slenderness, and it is important to consider the effect of uncertainty in $\omega$ on these columns. The distribution of $P_{u-r a n d}$ for a typical column (R1L1200) is shown in Figure 11. In the figure, $P_{u-r a n d}$ is normalized by $P_{u-E X P}$. It is found that the distribution of $\mathrm{P}_{\mathrm{u}-\text { rand }} / \mathrm{P}_{\mathrm{u}-\mathrm{EXP}}$ can be fitted by a normal distribution.

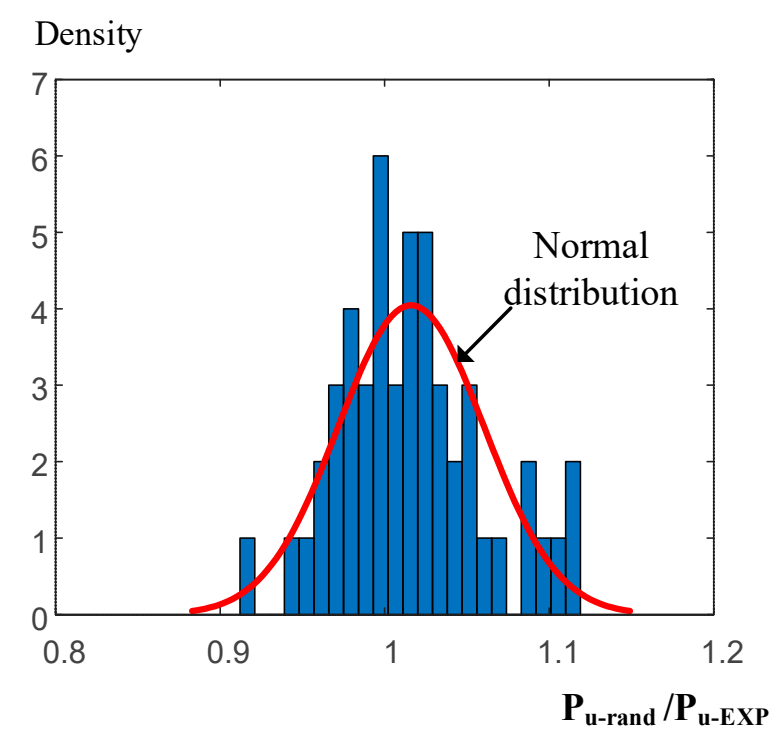

Figure 11. Histograms of $\mathrm{P}_{\mathrm{u}-\text { rand }} / \mathrm{P}_{\mathrm{u}-\mathrm{EXP}}$ for R1L1200.

\section{Conclusions}

In this paper, a new approach for modelling initial localized imperfection $(\omega)$ is introduced. The proposed approach considers uncertainty in $\omega$ and is based on superposition of Fourier series expansion of different functions. The Fourier series-based 3D models for the columns with random $\omega$ were generated by MATLAB, and were then imported into ABAQUS to conduct the FE analysis. The studied stainless steel columns with cold-formed RHS and SHS are selected among the tested specimens reported in the literature. The selected columns have relatively higher cross-sectional slenderness to ensure that they undergo cross-sectional local buckling reduction prior to failure. On the basis of this study, it is found that both the coefficients of variation and the maximum value of absolute error for the predicted results increase as cross-sectional slenderness increases. This is because columns with larger cross-sectional slenderness are sensitive to initial localized imperfection and, consequently, the change in the value of modelled localized imperfection can lead to much discrepancy in the ultimate compressive strength. Therefore, the effect of uncertainty in $\omega$ on the columns with larger cross-sectional slenderness requires a careful probabilistic consideration that should be considered in practical design, in which deterministic methods are often employed. 
Author Contributions: Writing the paper, Y.S.; Supervision, R.C.

Funding: This research was funded by the Project BIA2016-75678-R, AEI/FEDER, UE “Comportamiento estructural de pórticos de acero inoxidable. Seguridad frente a acciones accidentales de sismo y fuego", funded from the MINECO (Spain).

Acknowledgments: The first author acknowledges the financial support from China Scholarship Council. The authors acknowledge the financial support provided by the Project BIA2016-75678-R, AEI/FEDER, UE "Comportamiento estructural de pórticos de acero inoxidable. Seguridad frente a acciones accidentales de sismo y fuego", funded from the MINECO (Spain).

Conflicts of Interest: The authors declare no conflict of interest.

\section{References}

1. Rossi, B. Discussion on the Use of Stainless Steel in Constructions in View of Sustainability. Thin. Wall. Struct. 2014, 83, 182-189. [CrossRef]

2. Zitelli, C.; Paolo Folgarait, P.; Schino, A.D. Laser Powder Bed Fusion of Stainless Steel Grades: A Review. Metals 2019, 9, 731. [CrossRef]

3. Baddoo, N. Design Guide 27: Structural Stainless Steel; American Institute of Steel Construction (AISC): Chicago, IL, USA, 2013.

4. Chen, X.M.; Xia, J.W.; Xu, B.; Ma, R.W. Mechanical Performance of Built-Up Columns Composed of Four Cold-Formed Square Steel Tubes. Appl. Sci. 2019, 9, 1204. [CrossRef]

5. Li, H.T.; Young, B. Design of cold-formed high strength steel tubular sections undergoing web crippling. Thin. Wall. Struct. 2018, 133, 192-205. [CrossRef]

6. López-Colina, C.; Serrano, M.A.; Lozano, M.; Gayarre, F.L.; Suárez, J. Simplified Models for the Material Characterization of Cold-Formed RHS. Materials 2017, 10, 1043. [CrossRef] [PubMed]

7. Serrano, M.A.; López-Colina, C.; Gayarre, F.L.; Wilkinson, T.; Suárez, J. The Resistance of Welded Joints of Galvanized RHS Trusses with Different Vent Hole Geometries. Appl. Sci. 2019, 9, 1553. [CrossRef]

8. Li, H.T.; Young, B. Material properties of cold-formed high strength steel at elevated temperatures. Eng. Struct. 2017, 141, 571-583. [CrossRef]

9. Li, H.T.; Young, B. Behaviour of cold-formed high strength steel RHS under localised bearing forces. Eng. Struct. 2019, 183, 1049-1058. [CrossRef]

10. Jo, B.; Okamoto, K.; Kasahara, N. Creep Buckling of 304 Stainless-Steel Tubes Subjected to External Pressure for Nuclear Power Plant Applications. Metals 2019, 9, 536. [CrossRef]

11. Li, H.T.; Young, B. Cold-formed ferritic stainless steel tubular structural members subjected to concentrated bearing loads. Eng. Struct. 2017, 145, 392-405. [CrossRef]

12. Peng, Y.; Chu, J.; Jun Dong, J. Compressive Behavior and Constitutive Model of Austenitic Stainless Steel S30403 in High Strain Range. Materials 2018, 11, 1023. [CrossRef] [PubMed]

13. Corradi, M.; Osofero, A.I.; Borri, A. Repair and Reinforcement of Historic Timber Structures with Stainless Steel-A Review. Metals 2019, 9, 106. [CrossRef]

14. Yrjola, P.; Saynajakangas, J.; Soderberg, K. Stainless Steel Hollow Sections Handbook; Finnish Constructional Steelwork Association: Helsinki, Finland, 2008.

15. COPRA Reference Manual; Data M Sheet Metal Solutions GmbH: Valley, Germany, 2014.

16. Nagamachi, T.; Nakako, T.; Nakamura, D. Effects of Roll Diameter and Offset on Sectional Shape of Square Steel Pipe Processed by Roll Forming. Mater. Trans. 2011, 52, 2159-2164. [CrossRef]

17. Gardner, L.; Nethercot, D.A. Numerical Modeling of Stainless Steel Structural Components-A Consistent Approach. J. Struct. Eng. 2004, 130, 1586-1601. [CrossRef]

18. Wang, J.; Afshan, S.; Schillo, N.; Theofanous, M.; Feldmann, M.; Gardner, L. Material properties and compressive local buckling response of high strength steel square and rectangular hollow sections. Eng. Struct. 2017, 130, 297-315. [CrossRef]

19. Zhao, O.; Gardner, L.; Young, B. Experimental Study of Ferritic Stainless Steel Tubular Beam-Column Members Subjected to Unequal End Moments. J. Struct. Eng. 2016, 142, 04016091. [CrossRef]

20. Zhao, O.; Rossi, B.; Gardner, L.; Young, B. Behaviour of structural stainless steel cross-sections under combined loading - Part I: Experimental study. Eng. Struct. 2015, 89, 236-246. [CrossRef] 
21. Young, B.; Lui, W.M. Behavior of Cold-Formed High Strength Stainless Steel Sections. J. Struct. Eng. 2005, 131, 1738-1745. [CrossRef]

22. Lui, W.M.; Ashraf, M.; Young, B. Tests of cold-formed duplex stainless steel SHS beam-columns. Eng. Struct. 2014, 74, 111-121. [CrossRef]

23. Li, H.T.; Young, B. Cold-formed high strength steel SHS and RHS beams at elevated temperatures. J. Constr. Steel. Res. 2019, 158, 475-485. [CrossRef]

24. AISI S100-16 North American Specification for the Design of Cold-Formed Steel Structural Members, 2016th ed.; American Iron and Steel Institute (AISC): Washington, DC, USA, 2016.

25. Zheng, B.F.; Shu, G.P.; Xin, L.C.; Yang, R.; Jiang, Q.L. Study on the Bending Capacity of Cold-formed Stainless Steel Hollow Sections. Structures 2016, 8, 63-74. [CrossRef]

26. Arrayago, I.; Real, E.; Mirambell, E. Experimental study on ferritic stainless steel RHS and SHS beam-columns. Thin. Wall. Struct. 2016, 100, 93-104. [CrossRef]

27. Theofanous, M.; Gardner, L. Testing and numerical modelling of lean duplex stainless steel hollow section columns. Eng. Struct. 2009, 31, 3047-3058. [CrossRef]

28. Huang, Y.; Young, B. Tests of pin-ended cold-formed lean duplex stainless steel columns. J. Constr. Steel. Res. 2013, 82, 203-215. [CrossRef]

29. Afshan, S.; Gardner, L. Experimental Study of Cold-Formed Ferritic Stainless Steel Hollow Sections. J. Struct. Eng. 2013, 139, 717-728. [CrossRef]

30. Bock, M.; Arrayago, I.; Real, E. Experiments on cold-formed ferritic stainless steel slender sections. J. Constr. Steel. Res. 2015, 109, 13-23. [CrossRef]

31. Arrayago, I.; Real, E. Experimental Study on Ferritic Stainless Steel RHS and SHS Cross-sectional Resistance Under Combined Loading. Structures 2015, 4, 69-79. [CrossRef]

32. Minitab 18 Reference Manual; Minitab, LLC: State College, PA, USA, 2019.

33. JG/T 178-2005 Cold-Formed Steel Hollow Sections for Building Structures; Standards Press of China: Beijing, China, 2005.

34. CEN, EN-10219-2:2006 Cold Formed Welded Structural Hollow Sections of Non-Alloy and Fine Grain Steels. Part 2: Tolerances, Dimensions and Sectional Properties; European Committee for Standardization: Brussels, Belgium, 2006.

35. Davis, J.C. Statistics and Data Analysis in Geology, 3rd ed.; Wiley \& Sons: New York, NY, USA, 1973.

36. Higgins, J.R. Sampling Theory in Fourier and Signal Analysis: Foundations, 1st ed.; Clarendon Press: Oxford, UK, 1996.

37. Young, B.; Lui, W.M. Tests of cold-formed high strength stainless steel compression members. Thin. Wall. Struct. 2006, 44, 224-234. [CrossRef]

38. Young, B.; Liu, Y.H. Experimental Investigation of Cold-Formed Stainless Steel Columns. J. Struct. Eng. 2003, 129, 169-176. [CrossRef]

39. Gardner, L.; Nethercot, D.A. Experiments on stainless steel hollow sections-Part 2: Member behavior of columns and beams. J. Constr. Steel. Res. 2004, 60, 1319-1332. [CrossRef]

40. Arrayago, I.; Rasmussen, K.J.R.; Real, E. Full slenderness range DSM approach for stainless steel hollow cross-sections. J. Constr. Steel. Res. 2017, 133, 156-166. [CrossRef]

41. Arrayago, I.; Rasmussen, K.J.R.; Real, E. Full slenderness range DSM approach for stainless steel hollow cross-section columns and beam-columns. J. Constr. Steel. Res. 2017, 138, 246-263. [CrossRef]

42. Abaqus, v. 6.13 Reference Manual; Simulia, Dassault Systemes: Johnston, RI, USA, 2013.

43. MATLAB 2017(b) Reference Manual; The MathWorks: Natick, MA, USA, 2019.

44. Riks, E. An incremental approach to the solution of snapping and buckling problems. Int. J. Solids Struct. 1979, 15, 529-551. [CrossRef]

45. Jandera, M.; Machacek, J. Residual stress influence on material properties and column behavior of stainless steel SHS. Thin. Wall. Struct. 2014, 83, 12-18. [CrossRef]

(C) 2019 by the authors. Licensee MDPI, Basel, Switzerland. This article is an open access article distributed under the terms and conditions of the Creative Commons Attribution (CC BY) license (http://creativecommons.org/licenses/by/4.0/). 